\title{
Clinical characteristics of adult T-cell leukemia/lymphoma infiltration in the gastrointestinal tract
}

\author{
Tadashi Miike ${ }^{1,2^{*}+} \mathbb{D}$, Hiroshi Kawakami ${ }^{1,3+}$, Takuro Kameda ${ }^{2}$, Shojiro Yamamoto ${ }^{1,2}$, Yoshihiro Tahara ${ }^{1,2}$, \\ Tomonori Hidaka ${ }^{2}$, Yoko Kubuki ${ }^{2}$, Kenji Yorita ${ }^{4}$, Yutaka Akiyama ${ }^{5}$, Yasuji Arimura ${ }^{6}$, Yoshimasa Kubota ${ }^{1,3}$, \\ Hiroaki Kataoka ${ }^{5}$ and Kazuya Shimoda ${ }^{2}$
}

\begin{abstract}
Background: Adult T-cell leukemia/lymphoma (ATLL) is a peripheral T-cell malignancy caused by human T-cell leukemia virus type 1. The clinical course of ATLL is very heterogeneous, and many organs, including the gastrointestinal (Gl) tract, can be involved. However, there are few detailed reports on ATLL infiltration in the Gl tract. We investigated the clinical characteristics of ATLL infiltration in the Gl tract.

Methods: This retrospective observational single-center study included 40 consecutive ATLL patients who underwent Gl endoscopy. The patients' demographic and clinical characteristics and endoscopic findings were analyzed retrospectively. Patients with ATLL who were diagnosed by histological examination were divided into two groups based on Gl tract infiltration.

Results: Multivariate analysis revealed that the absence of skin lesions was significantly associated with Gl infiltration $(P<0.05)$. Furthermore, the infiltration group tended to have similar macroscopic lesions in the upper and lower $\mathrm{Gl}$ tracts, such as diffuse type, tumor-forming type, and giant-fold type.
\end{abstract}

Conclusions: Gl endoscopy may be considered for ATLL patients without skin lesions.

Keywords: Adult T-cell leukemia/lymphoma, Gl tract infiltration, Irregular blood vessels, Obscure glandular structures, Skin lesion

\section{Background}

Adult T-cell leukemia/lymphoma (ATLL) is a peripheral $\mathrm{T}$-cell malignancy caused by human $\mathrm{T}$-cell leukemia virus type 1 (HTLV-1) [1-3]. HTLV-1 infection is usually transmitted vertically, and ATLL develops for several

\footnotetext{
* Correspondence: tadashi_miike@med.miyazaki-u.ac.jp

${ }^{\dagger}$ Tadashi Miike and Hiroshi Kawakami contributed equally to this work.

'Department of Gastroenterology and Hepatology, Division of Endoscopy and Center for Digestive Disease, University of Miyazaki Hospital, 5200 Kihara, Kiyotake, Miyazaki 889-1692, Japan

${ }^{2}$ Division of Gastroenterology and Hematology, Department of Internal Medicine, Faculty of Medicine, University of Miyazaki, 5200 Kihara, Kiyotake, Miyazaki 889-1692, Japan

Full list of author information is available at the end of the article
}

years. The clinical course of ATLL is very heterogeneous, and many organs, including the gastrointestinal (GI) tract, can be involved. B cell malignant lymphoma was recently shown to invade the GI tract and result in clinically detectable findings [4-9]; however, there are few detailed reports on ATLL infiltration into the GI tract. The standard macroscopic classification of ATLL has not yet been established. However, Sakata et al. previously investigated 76 patients of ATLL involvement in the GI tract. They described that the most typical configurations were three types, such as diffuse, tumorforming, giant fold [10]. This study investigates the characteristics of ATLL infiltration in the GI tract. The

(c) The Author(s). 2020 Open Access This article is licensed under a Creative Commons Attribution 4.0 International License, which permits use, sharing, adaptation, distribution and reproduction in any medium or format, as long as you give appropriate credit to the original author(s) and the source, provide a link to the Creative Commons licence, and indicate if changes were made. The images or other third party material in this article are included in the article's Creative Commons licence, unless indicated otherwise in a credit line to the material. If material is not included in the article's Creative Commons licence and your intended use is not permitted by statutory regulation or exceeds the permitted use, you will need to obtain permission directly from the copyright holder. To view a copy of this licence, visit http://creativecommons.org/licenses/by/4.0/ The Creative Commons Public Domain Dedication waiver (http://creativecommons.org/publicdomain/zero/1.0/) applies to the data made available in this article, unless otherwise stated in a credit line to the data. 
current retrospective study was conducted to evaluate whether ATLL infiltration in the GI tract was related to the skin lesion.

\section{Methods}

\section{Patients and study design}

In this retrospective observational study, the demographic and clinical data of 40 consecutive ATLL patients who underwent GI endoscopy between April 1, 2009 and December 31, 2015 at the University of Miyazaki Hospital were analyzed. ATLL was diagnosed according to the Japan Clinical Oncology GroupLymphoma Study Group criteria (Shinoyama criteria) [11] and classified as four clinical subtypes: acute, lymphoma, chronic, and smoldering. Patients with the acute type are defined as remaining ATLL patients, who usually have leukemic manifestations and tumor lesions. Patients with the lymphoma type are defined as having no lymphocytosis, $1 \%$ or more abnormal $\mathrm{T}$ lymphocytes, and histologically proven lymphadenopathy with or without extranodal lesions. Patients with the chronic type are defined as having absolute lymphocytosis $(\geq 4 \times$ $10^{9} / \mathrm{L}$ ) with a T lymphocyte count $>3.5 \times 10^{9} / \mathrm{L}$; a lactate dehydrogenase value up to twice the normal upper limit; no hypercalcemia; no involvement of the central nervous system, bone, or GI tract; and no ascites or pleural effusion. Further, lymphadenopathy and involvement of the liver, spleen, skin, and lungs may be present, and $5 \%$ or more abnormal $\mathrm{T}$ lymphocytes are seen in the peripheral blood in most cases. Patients with the smoldering type are defined as having $5 \%$ or more abnormal $\mathrm{T}$ lymphocytes in the peripheral blood; a normal lymphocyte level $\left(<4 \times 10^{9} / \mathrm{L}\right) ;$ no hypercalcemia (corrected calcium level $<2.74 \mathrm{mmol} / \mathrm{L}$ ); a lactate dehydrogenase value up to $1.5 \times$ the normal upper limit; no lymphadenopathy; no involvement of the liver, spleen, central nervous system, bone, or GI tract; and no ascites or pleural effusion. Further, skin and pulmonary lesions may be present, and if there are fewer than 5\% abnormal $\mathrm{T}$ lymphocytes in the peripheral blood, either histologically proven skin lesions or pulmonary lesions should be present. ATLL diagnoses were made based on anti-HTLV-1 positivity in sera and the presence of malignant mature T-cells.

The study included patients who performed upper GI endoscopy for ATLL. Exclusion criteria included age less than 20 years, a performance status value greater than 4 , mental disability, contrast medium allergy, severe heart disease (New York Heart Association class III or IV heart failure), severe pulmonary disease (peripheral oxygen saturation $<90 \%$ ), actual or possible pregnancy, women wishing to become pregnant, nursing mothers, and refusal to provide informed consent.

Macroscopic GI findings were classified as follows: diffuse type (including multiple ulcers and diffuse erosions), tumor-forming type (including submucosal tumor-like lesion, multiple polypoid lesions, and tumor with ulceration), and giant-fold type, as previously described [10]. Endoscopic examinations were performed using GI endoscopes that emitted white light. If ATLL infiltrated their GI tracts, magnifying endoscopes (GIFQ240Z, H260Z, PCF-Q260AZI, CF-H260AZI, Olympus, Tokyo, Japan) were used instead of a conventional endoscope. Image-enhanced endoscopy (IEE) findings were assessed by one specialist (TM). We did not perform random biopsies from GI tract. We also performed a small intestinal examination using the whole-body computed tomography $(\mathrm{CT})$, but we did not perform capsule endoscopy or double-balloon endoscopy routinely.

This study was approved by the Research Ethics Committee of the Faculty of Medicine, University of Miyazaki (IRB approval number: O-0003) and performed in accordance with the provisions of the Declaration of Helsinki (as revised in Fortaleza, Brazil, October 2013).

\section{Statistical analysis}

Patients were divided into the infiltration and noninfiltration groups based on whether ATLL infiltrated the GI tract. The definition of ATLL infiltration into the GI tract was both endoscopically and pathologically positive findings. Descriptive statistics such as mean, odds ratios (OR) and 95\% confidence intervals (CI) were calculated. Inferential statistical methods such as Chi-squared test and multivariate logistic regression were also applied to assess potential associations between infiltration and non-infiltration, respectively. A $P$-value below 0.05 was considered as the statistical significance level through bivariate analysis and $P<0.1$ for selecting the variables to introduce into the multivariate regression model. Discrete variables of four clinical subtypes investigated were global assessment of change compared with baseline $(4$ points ordinal scale: acute $=0$, lymphoma $=1$, chronic $=2$, smoldering $=3$ ) for the order of priority of good prognosis. All analyses were performed using STAT A/SE 14.2 (Stata Corp., College Station, TX, USA).

\section{Results}

Patients' clinical characteristics are summarized in Table 1. All 40 patients who provided consent in this study underwent upper GI endoscopy, while 29 patients underwent both upper and lower GI endoscopy. However, the remaining 11 patinets with poor physical conditions, informed consent could not be obtained for lower GI endoscopy. Positive findings, such as Candidal esophagitis, ulcers, erosions, tumor-forming lesions, and diffuse fold lesions, were observed in 22 of the 40 patients who underwent GI endoscopy. Positive findings were observed in 21 of the 40 patients who underwent upper GI endoscopy. Positive findings were observed in 
Table 1 Characteristics of 40 patients with adult T-cell leukemia/lymphoma

\begin{tabular}{ll}
\hline Age, median (range) (years) & $67.5(40-84)$ \\
Gender, $\mathrm{n}(\%) / \mathrm{n}(\%)($ male/female) & $23(57.5 \%) / 17(42.5 \%)$ \\
Digestive symptoms, $\mathrm{n}(\%) / \mathrm{n}(\%)(+/-)^{\mathrm{a}}$ & $11(27.5 \%) / 29(72.5 \%)$ \\
Clinical subtypes of ATLL, & $23(57.5 \%) / 6(15.0 \%) / 5(12.5 \%) / 6(15.0 \%)$ \\
$\mathrm{n}(\%) / \mathrm{n}(\%) / \mathrm{n}(\%) / \mathrm{n}(\%)($ acute/lymphoma/chronic/smoldering) & \\
Superficial lymphadenopathy, & $26(65.0 \%) / 14(35.0 \%)$ \\
$\mathrm{n}(\%) / \mathrm{n}(\%)(+/-)$ & $17(42.5 \%) / 23(57.5 \%)$ \\
Hepatosplenomegaly, $\mathrm{n}(\%) / \mathrm{n}(\%)(+/-)$ & $26(65.0 \%) / 14(35.0 \%)$ \\
Skin lesions, $\mathrm{n}(\%) / \mathrm{n}(\%)(+/-)$ & $15(37.5 \%) / 25(62.5 \%)$ \\
Opportunistic infections, $\mathrm{n}(\%) / \mathrm{n}(\%)(+/-)^{\mathrm{b}}$ &
\end{tabular}

${ }^{\mathrm{a}}$ Digestive symptoms include nausea, diarrhea, epigastralgia, anorexia, and tarry and bloody stools

${ }^{b}$ Opportunistic infections include herpes zoster, cytomegalovirus infection, pneumonia (mycotic, mycobacterial, pneumocystis), Candidal esophagitis, and enteritis ATLL, Adult T-cell leukemia/lymphoma; +, positive; -, negative

6 of the 29 patients who underwent lower GI endoscopy (Table 2). We observed Candidal esophagitis in 5 patients, gastric ulcers in 10 patients, gastric erosions in 1 patient, gastric tumor-forming lesions in 3 patients, diffuse gastric fold lesions in 3 patients, duodenal ulcers in 1 patient, duodenal erosions in 2 patients, colonic ulcers in 2 patients, colonic tumor-forming lesions in 2 patients, and diffuse colonic fold lesions in 2 patients, respectively. Biopsy examinations were subsequently performed for histological diagnosis. Of the 22 patients of the 40 total patients who had upper/lower GI tract endoscopic findings, 12 were diagnosed with ATLL infiltration in the GI tract by histological examination (Table 3). Ten patients were diagnosed with ATLL infiltration in the stomach by histological examination. Two patients had no findings in the stomach. Six patients were diagnosed with ATLL infiltration in the colon by histological examination. Two patients had no findings in the colon. Four patients had none available in the colon. Four of the six patients had both gastric and colonic lesions.

All 40 patients underwent $\mathrm{CT}$ and ${ }^{18} \mathrm{~F}$-fluorodeoxyglucose (FDG) positron emission tomography-CT, respectively. One patient revealed an abdominal uptake of FDG in the ileum. Therefore, we performed doubleballoon endoscopy and diagnosed diffuse type of ATLL in the small intestine, which was in concordance with abnormal uptake of FDG. Upper GI endoscopy showed findings such as scattered reddish protruding lesions, diffuse ulcerative lesions, and localized/diffuse areas of coarse mucosal granularity (Figs. 1, 2 and 3). Five patients only underwent IEE because of non-overt subjective symptoms and progression of illness at this time. IEE showed cases of obscure glandular structures and irregular bifurcated meandering blood vessels (Fig. 4). Lower GI endoscopy showed similar colonic findings to IEE.

All ATLL patients did not have GI adverse events during chemotherapy. Thus, we could not examine the endoscopic follow-up with a poor prognosis.

Univariate analysis showed no significant difference between the infiltration and non-infiltration groups in terms of clinical features (Table 4). However, digestive symptoms $(P=0.045)$ and acute-type and lymphomatype ATLL $(P=0.053)$ were more prevalent in the infiltration group, and skin lesions were significantly more prevalent in the non-infiltration group $(P=0.009)$.

Table 2 Proportion of patients with positive findings and adult T-cell leukemia/lymphoma infiltration in the gastrointestinal tract ${ }^{a}$

\begin{tabular}{|c|c|c|c|}
\hline Examination & Number & $\begin{array}{l}\text { Positive findings, \% }(n / n) \\
55 \%(22 / 40)\end{array}$ & $\begin{array}{l}\text { ATLL infiltration, \% (n/n) } \\
30 \%(12 / 40)\end{array}$ \\
\hline \multirow{2}{*}{$\begin{array}{l}\text { Upper } \\
\text { Gl endoscopy }\end{array}$} & \multirow[t]{2}{*}{$n=40$} & $53 \%(21 / 40)$ & $52 \%(11 / 21)$ \\
\hline & & $\begin{array}{l}\text { Esophagus: } 5 \\
\text { Stomach: } 16 \\
\text { Duodenum: } 3\end{array}$ & $\begin{array}{l}\text { Esophagus: } 0 \\
\text { Stomach: } 10 \\
\text { Duodenum: } 2\end{array}$ \\
\hline \multirow{2}{*}{$\begin{array}{l}\text { Lower } \\
\text { Gl endoscopy }\end{array}$} & \multirow[t]{2}{*}{$n=29$} & $21 \%(6 / 29)$ & $100 \%(6 / 6)$ \\
\hline & & $\begin{array}{l}\text { Small intestine }{ }^{\mathrm{b}} 5 \\
\text { Large intestine } 6\end{array}$ & $\begin{array}{l}\text { Small intestine } 5 \\
\text { Large intestine } 6\end{array}$ \\
\hline
\end{tabular}

${ }^{a}$ Characteristics of upper and lower Gl endoscopic findings include duplicative cases

bTerminal ileum and cecum

ATLL Adult T-cell leukemia/lymphoma, GI Gastrointestinal 
Table 3 Macroscopic findings of 12 patients with adult T-cell leukemia/lymphoma infiltration in the gastrointestinal tract

\begin{tabular}{|c|c|c|c|c|c|}
\hline \multirow{2}{*}{$\begin{array}{l}\text { Case } \\
\text { number }\end{array}$} & \multirow{2}{*}{$\begin{array}{l}\text { Age } \\
\text { (years) }\end{array}$} & \multirow[t]{2}{*}{ Gender } & \multirow{2}{*}{$\begin{array}{l}\text { Clinical } \\
\text { subtype } \\
\text { of ATLL }\end{array}$} & \multicolumn{2}{|c|}{ Macroscopic findings ${ }^{a}$} \\
\hline & & & & Stomach & Colon \\
\hline 1 & $70-80$ & 2 & Lymphoma & Diffuse & NA \\
\hline 2 & $60-70$ & 2 & Lymphoma & Tumor-forming & Tumor-forming \\
\hline 3 & $60-70$ & 1 & Acute & Tumor-forming & NA \\
\hline 4 & $60-70$ & 1 & Acute & Diffuse & Diffuse \\
\hline 5 & $70-80$ & 1 & Acute & Diffuse & Diffuse \\
\hline 6 & $60-70$ & 1 & Acute & Tumor-forming & No findings \\
\hline 7 & $60-70$ & 2 & Acute & Diffuse & NA \\
\hline 8 & $70-80$ & 2 & Acute & Giant-fold & Giant-fold \\
\hline 9 & $70-80$ & 1 & Acute & No findings & Giant-fold \\
\hline 10 & $70-80$ & 2 & Acute & Giant-fold & No findings \\
\hline 11 & $80-90$ & 2 & Lymphoma & Diffuse & NA \\
\hline 12 & $60-70$ & 2 & Acute & No findings & Tumor-forming \\
\hline
\end{tabular}

The identifying information (e.g. age and gender) were anonymized a Macroscopic Gl findings were classified as follows: diffuse type, tumorforming type, and giant-fold type, as previously described [10]

ATLL Adult T-cell leukemia/lymphoma, NA not available

Multivariate analysis revealed that ATLL infiltration in the GI tract was significantly associated with the absence of skin lesions $(P=0.041)$ (Table 5).

\section{Discussion}

ATLL is a systemic disease with an unfavorable prognosis, and any organ can be impaired by ATLL cell infiltration. We observed endoscopic characteristic findings of ATLL infiltration in the GI tract in 12 patients (30\%). Previous studies have also reported a prevalence of about 30\% [10, 12]. Moreover, in our study, IEE showed that ATLL infiltration in the GI tract is characterized by obscure glandular structures and irregular bifurcated meandering blood vessels.

Our study presents several novel findings. Firstly, we observed a correlation between gastric and colonic lesions. Nakamura et al. previously proposed that, in GI infiltration, the stomach and intestine would present different ATLL lesion types [13]. However, our study shows similar macroscopic findings in the stomach and colon, even though it is generally accepted that the macroscopic forms of ATLL vary throughout the GI tract. Therefore, endoscopy is necessary for both regions to closely evaluate GI tract infiltration. Secondly, we observed obscure glandular structures and irregular bifurcated meandering blood vessels on the magnified endoscopic images of five ATLL patients with GI tract infiltration. These findings seem characteristic of lymphoproliferative diseases. Nonaka et al. [4] found that

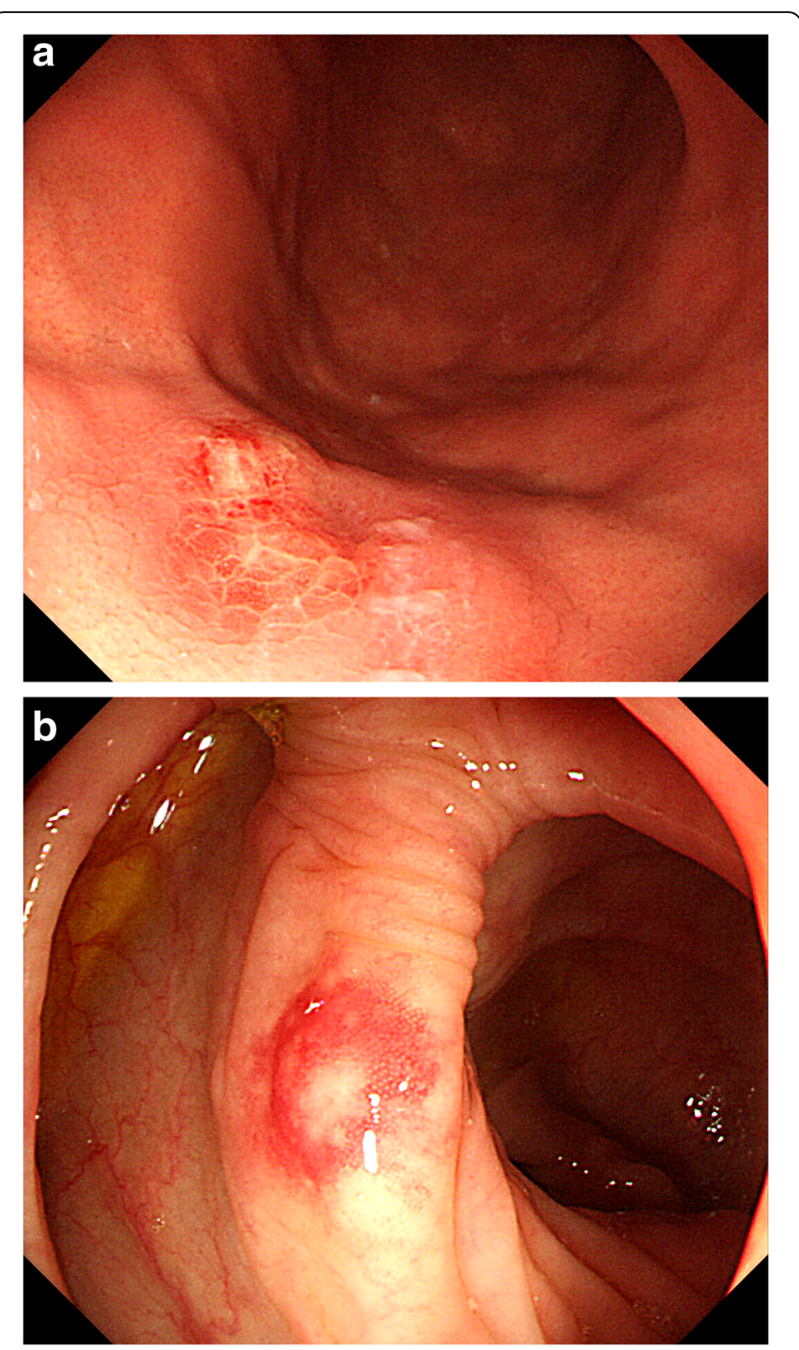

Fig. 1 Macroscopic gastrointestinal findings. a A 60s-year-old person underwent endoscopy for screening purposes. Upper gastrointestinal (GI) endoscopy shows scattered reddish mucosal protrusions on the greater curvature of the gastric body. $\mathbf{b}$ Colonoscopy image shows sporadic protrusions

magnified endoscopic images from the narrow-band imaging of gastric mucosa-associated lymphoid tissue lymphoma present obscure glandular structures and irregular blood vessels with minimal changes in size and caliber, despite lymphoma cell infiltration. These common features between B cell lymphoma and ATLL may be caused by lymphoma cell infiltration in stromal tissue, the concomitant destruction of glandular structures, and neoplastic growth. The displacement of superficial vessels caused by proliferating lymphoid tissue may have resulted in the minimal size and caliber changes and meandering observed. Moreover, the destruction of glandular structures may be caused by the initial diffuse permeation of ATLL cells around the muscularis mucosa, 

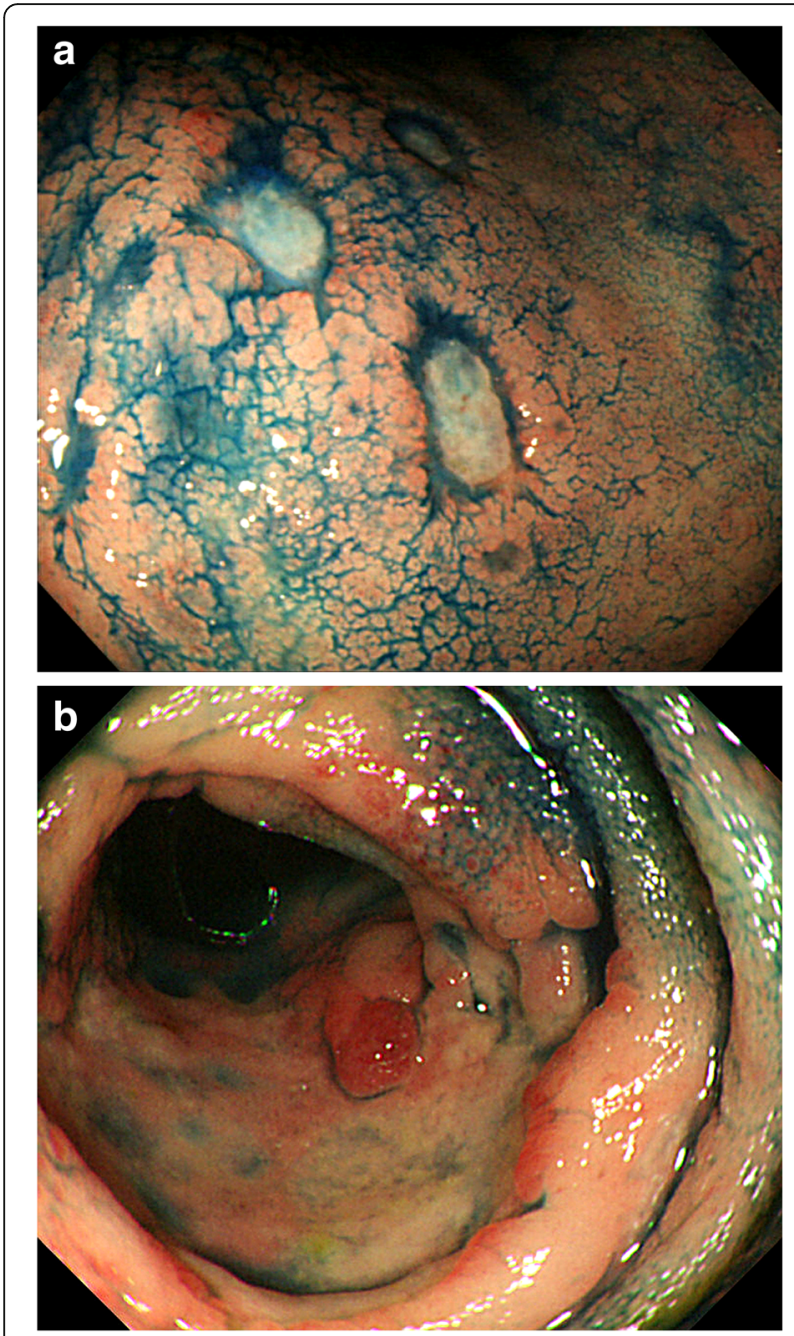

Fig. 2 Macroscopic gastrointestinal findings. a A 70s-year-old person underwent endoscopy due to a tarry stool. Upper Gl endoscopy shows diffusely ulcerative mucosa on the anterior wall of the gastric body. b Colonoscopy image shows sporadic ulceration followed by the aforementioned changes in blood and lymphatic vessels.

Furthermore, we found that patients with digestive symptoms, and no skin lesions may have a high risk of GI tract infiltration. Our multivariate analysis showed that the absence of skin lesions significantly correlated with ATLL infiltration in the GI tract. Skin lesions have been observed in about half of all ATLL patients [11] and are more prevalent in patients with chronic-type or smoldering-type ATLL than in those with acute-type or lymphoma-type ATLL. Additionally, aggressive ATLL may be more likely to infiltrate the GI tract [14-18]. We recommended physicians be more attentive to the lack of skin lesions in ATLL patients.
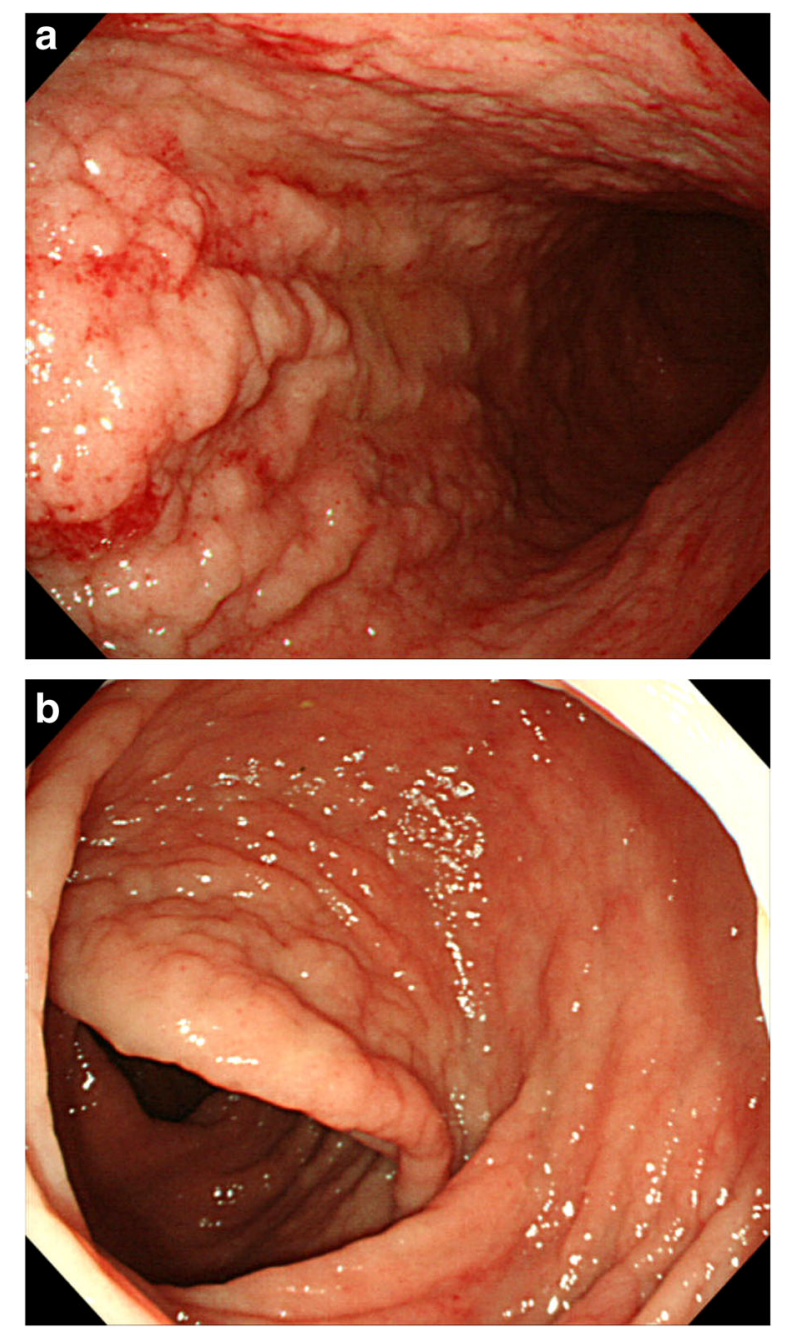

Fig. 3 Macroscopic gastrointestinal findings. a A 70s-year-old person underwent endoscopy due to diarrhea.

Esophagogastroduodenoscopy shows diffuse areas of coarse mucosal granularity on the greater curvature of the gastric body. $\mathbf{b}$ Colonoscopy image shows sporadic diffuse granularity

Although this study provides useful data regarding ATLL infiltration in the GI tract, it has several limitations related to its observational, non-randomized, single-center, and retrospective design. Firstly, selection bias for both groups could not be avoided because there were no assessments of real-time diagnosis performance. Secondly, because ATLL has an unfavorable prognosis, it was difficult to perform GI endoscopy multiple times when investigating GI tract infiltration. Thirdly, IEE findings were assessed by one specialist at a single institution. Fourthly, the number of cases was limited. Fifthly, All ATLL patients did not undergo colonoscopy. More cases are needed to clarify the usefulness of IEE in diagnosing ATLL infiltration in the GI tract. 

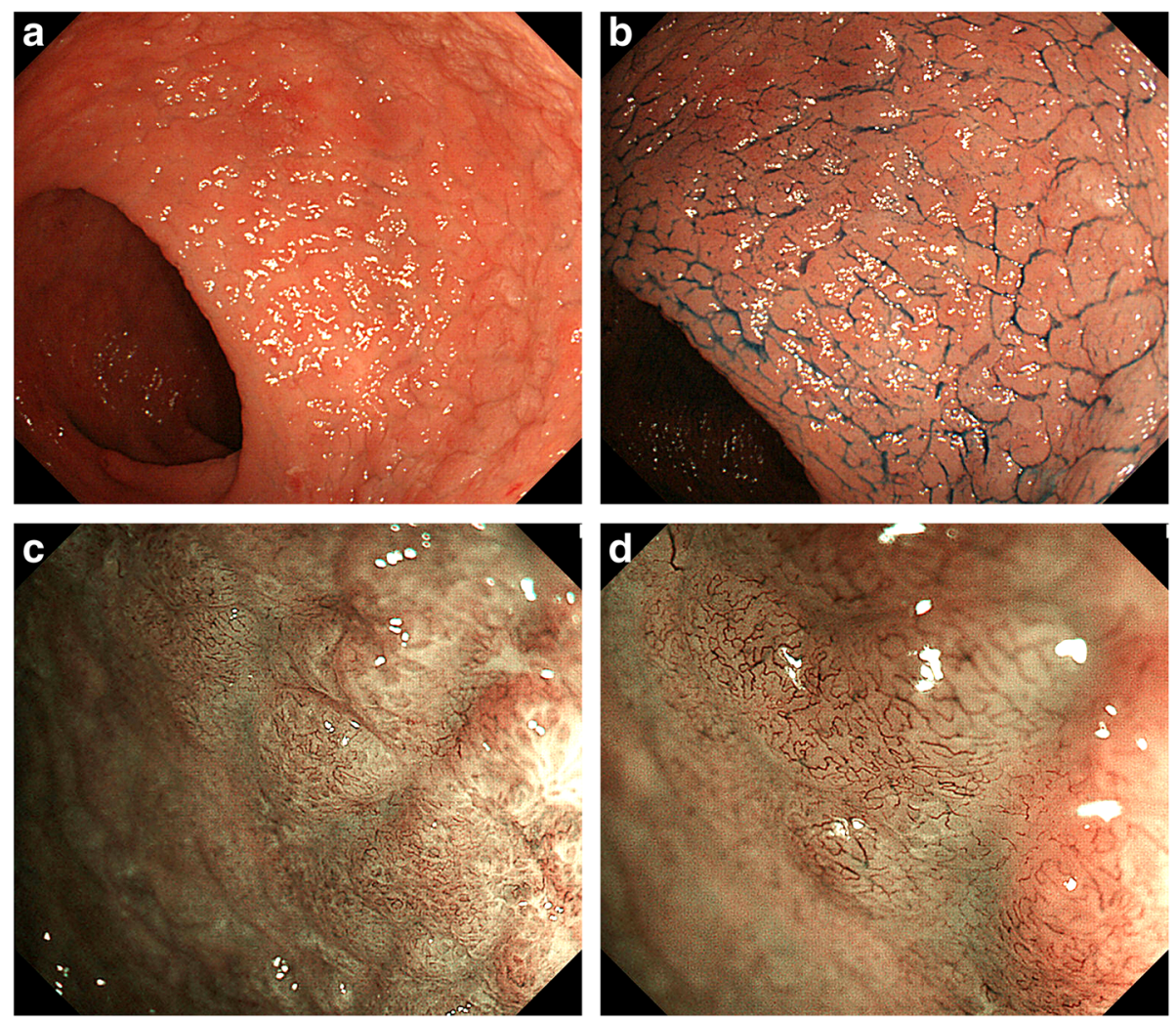

Fig. 4 Magnified endoscopic images on Image-enhanced endoscopy. a A 70s-year-old person underwent endoscopy due to epigastralgia and diarrhea. Colonoscopy shows diffuse areas of coarse mucosal granularity. $\mathbf{b}$ Chromoendoscopy with indigo carmine clearly shows coarse mucosal granularity. c Magnified endoscopic examination with narrow-band imaging (NBI) reveals obscure glandular structures. d Magnified endoscopic examination with NBI reveals irregular bifurcated meandering blood vessels

Table 4 Comparison of patients with and without adult T-cell leukemia/lymphoma infiltration in the gastrointestinal tract

\begin{tabular}{|c|c|c|c|}
\hline \multirow[t]{2}{*}{ Characteristics } & \multirow{2}{*}{$\begin{array}{l}\text { Infiltration } \text { group }^{a} \\
n=12\end{array}$} & \multirow{2}{*}{$\begin{array}{l}\text { Non-infiltration group } \\
n=28\end{array}$} & \multirow[t]{2}{*}{$P$-value } \\
\hline & & & \\
\hline Age, median (range) (years) & $69(61-82)$ & $66.5(40-84)$ & $0.585^{c}$ \\
\hline Gender, n (\%)/n (\%) (male/female) & $5(41.7 \%) / 7(58.3 \%)$ & $18(64.3 \%) / 10(35.7 \%)$ & $0.185^{d}$ \\
\hline $\begin{array}{l}\text { Digestive symptoms, } \\
\text { n (\%)/n (\%) (+/-) }\end{array}$ & $6(50.0 \%) / 6(50.0 \%)$ & $5(17.9 \%) / 23(82.1 \%)$ & $0.037^{d}$ \\
\hline $\begin{array}{l}\text { Clinical subtypes of ATLL, } \\
\mathrm{n}(\%) / \mathrm{n}(\%) / \mathrm{n}(\%) / \mathrm{n}(\%) \\
\text { (acute/lymphoma/chronic/smoldering) }\end{array}$ & $\begin{array}{l}9(75.0 \%) / 3(25.0 \%) \\
/ 0(0 \%) / 0(0 \%)\end{array}$ & $\begin{array}{l}14(50.0 \%) / 3(10.7 \%) \\
/ 5(17.8 \%) / 6(21.4 \%)\end{array}$ & $0.080^{d}$ \\
\hline $\begin{array}{l}\text { Superficial lymphadenopathy, } \\
\text { n (\%)/n (\%) (+/-) }\end{array}$ & 7 (58.3\%) /5 (41.7\%) & 19 (67.9\%) /9 (32.1\%) & $0.563^{d}$ \\
\hline $\begin{array}{l}\text { Hepatosplenomegaly, } \\
\text { n (\%)/n (\%) (+/-) }\end{array}$ & $6(50.0 \%) / 6(50.0 \%)$ & $11(39.3 \%) / 17(60.7 \%)$ & $0.530^{d}$ \\
\hline Skin lesions, n (\%)/n (\%) (+/-) & $4(33.3 \%) / 8(66.7 \%)$ & $22(78.6 \%) / 6(21.4 \%)$ & $0.006^{d}$ \\
\hline $\begin{array}{l}\text { Opportunistic infections, } \\
\text { n }(\%) / \text { n (\%) (+/-) }\end{array}$ & $4(33.3 \%) / 8(66.7 \%)$ & $11(39.3 \%) / 17(60.7 \%)$ & $0.722^{d}$ \\
\hline
\end{tabular}

\footnotetext{
${ }^{\mathrm{a} G r o u p ~ o f ~ A T L L ~ p a t i e n t s ~ w i t h ~ i n f i l t r a t i o n ~ i n ~ t h e ~ g a s t r o i n t e s t i n a l ~ t r a c t ~}$

${ }^{\mathrm{b}}$ Group of ATLL patients without infiltration in the gastrointestinal tract

c Wilcoxon (Mann-Whitney) test

${ }^{d}$ Chi-squared test

ATLL Adult T-cell leukemia/lymphoma
} 
Table 5 Statistical analysis of patients with and without adult T-cell leukemia/lymphoma infiltration in the gastrointestinal tract

\begin{tabular}{|c|c|c|c|c|c|c|}
\hline & \multirow[b]{2}{*}{ Odds ratio } & \multicolumn{3}{|c|}{ Univariate analysis } & \multicolumn{2}{|c|}{ Multivariate analysis } \\
\hline & & $95 \% \mathrm{Cl}$ & $P$-value & Odds ratio & $95 \% \mathrm{Cl}$ & $P$-value \\
\hline Age & 0.397 & $0.099-1.583$ & 0.190 & - & & \\
\hline Gender & 1.026 & $0.962-1.095$ & 0.436 & - & & \\
\hline Digestive symptoms & 4.600 & $1.038-20.381$ & 0.045 & 2.443 & $0.423-14.106$ & 0.318 \\
\hline Clinical subtypes of ATLL ${ }^{a}$ & 0.375 & $0.139-1.014$ & 0.053 & 0.468 & $0.165-1.329$ & 0.154 \\
\hline Superficial lymphadenopathy & 0.663 & $0.164-2.676$ & 0.564 & - & & \\
\hline Hepatosplenomegaly & 1.545 & $0.396-6.035$ & 0.531 & - & & \\
\hline Skin lesions & 0.136 & $0.030-0.6035$ & 0.009 & 0.184 & $0.036-0.934$ & 0.041 \\
\hline Opportunistic infections & 0.773 & $0.187-3.196$ & 0.722 & - & & \\
\hline
\end{tabular}

ATLL Adult T-cell leukemia/lymphoma, $\mathrm{Cl}$ Confidence interval

${ }^{a}$ Four clinical subtypes investigated were global assessment of change compared with baseline ( 4 points ordinal scale: acute $=0$, lymphoma $=1$, chronic $=2$, smoldering $=3$ ) for the order of priority of good prognosis

\section{Conclusions}

Physicians may perform GI endoscopy to actively investigate ATLL infiltration in the GI tract and evaluate the endoscopic findings characteristic of lymphoproliferative disease. The absence of skin lesions and the presence of characteristic endoscopic findings may help detect ATLL infiltration in the GI tract. GI endoscopy may be considered for ATLL patients without skin lesions.

\section{Abbreviations}

ATLL: Adult T-cell leukemia/lymphoma; HTLV-1: Human T-cell leukemia virus type 1; GI: Gastrointestinal; IEE: Image-enhanced endoscopy; CT: Computed tomography; OR: Odds ratio; Cl: Confidence interval; FDG

18F: fluorodeoxyglucose; NA: Not available; NBI: Narrow band imaging

\section{Acknowledgments}

Not applicable.

\section{Authors' contributions}

YK1 corresponding to Yoko Kubuki. YK2 corresponding to Yoshimasa Kubota. YA1 corresponding to Yutaka Akiyama. YA2 corresponding to Yasuji Arimura. HK1 corresponding to Hiroshi Kawakami. HK2 corresponding to Hiroaki Kataoka. TM and HK1 contributed equally to this work.TM, HK1, TK, SY, YT, $\mathrm{TH}, \mathrm{YK} 1, \mathrm{KY}, \mathrm{YA} 1, \mathrm{YK} 2, \mathrm{HK} 2$, and $\mathrm{KS}$ conducted the study. TM and YS performed endoscopy. TM, TK, TH and YK1 collected the data. TM assessed image enhanced endoscopic findings. TM, HK1, and YA2 interpreted the data. TM, HK1, and YA2 analyzed the data. KY, YA1, and HK2 performed the histological examination. TM and HK1 drafted the manuscript. All authors read and approved the final draft.

\section{Funding}

There was no funding for this study.

\section{Availability of data and materials}

The datasets used and/or analysed during the current study are available from the corresponding author (TM) on reasonable request.

\section{Ethics approval and consent to participate}

This study was conducted in accordance with the Declaration of Helsinki, and the study protocol was reviewed and approved by the Ethics Committees of the Research Ethics Committee of the Faculty of Medicine, University of Miyazaki (Approval number: O-0003). Informed consent was omitted and information of this study was disclosed in the form of opt-out on our hospital website. Information regarding the conduct of the research including the objectives was disclosed and the research subjects were provided an opportunity to refuse inclusion in the research.

\section{Consent for publication}

Not applicable.

\section{Competing interests}

The authors declare no conflicts of interest for this article.

\section{Author details}

'Department of Gastroenterology and Hepatology, Division of Endoscopy and Center for Digestive Disease, University of Miyazaki Hospital, 5200 Kihara, Kiyotake, Miyazaki 889-1692, Japan. ${ }^{2}$ Division of Gastroenterology and Hematology, Department of Internal Medicine, Faculty of Medicine, University of Miyazaki, 5200 Kihara, Kiyotake, Miyazaki 889-1692, Japan. ${ }^{3}$ Division of Gastroenterology and Hepatology, Department of Internal Medicine, Faculty of Medicine, University of Miyazaki, 5200 Kihara, Kiyotake, Miyazaki 889-1692, Japan. ${ }^{4}$ Department of Diagnostic Pathology, Kochi University Hospital, 185-1 Kohasu, Oko-cho, Nankoku, Kochi 783-8505, Japan. ${ }^{5}$ Section of Oncopathology and Regenerative Biology, Department of Pathology, Faculty of Medicine, University of Miyazaki, 5200 Kihara, Kiyotake, Miyazaki 889-1692, Japan. ${ }^{6}$ Clinical Research Support Center, University of Miyazaki Hospital, 5200 Kihara, Kiyotake, Miyazaki 889-1692, Japan.

Received: 20 January 2020 Accepted: 28 August 2020

Published online: 14 September 2020

\section{References}

1. Uchiyama T, Yodoi J, Sagawa K, Takatsuki K, Uchino H. Adult T-cell leukemia: clinical and hematologic features of 16 cases. Blood. 1977;50:481-92.

2. Poiesz BJ, Ruscetti FW, Gazdar AF, Bunn PA, Minna JD, Gallo RC. Detection and isolation of type $C$ retrovirus particles from fresh and cultured lymphocytes of a patient with cutaneous T-cell lymphoma. Proc Natl Acad Sci U S A. 1980;77:7415-9.

3. Ishitsuka K, Tamura K. Human T-cell leukemia virus type I and adult T-cell leukaemia-lymphoma. Lancet Oncol. 2014;15:e517-26.

4. Nonaka K, Ohata K, Matsuhashi N, Shimizu M, Arai S, Hiejima Y, et al. Is narrow-band imaging useful for histological evaluation of gastric mucosaassociated lymphoid tissue lymphoma after treatment? Dig Endosc. 2014;26: 358-64.

5. Norimura D, Fukuda E, Yamao T, Niino D, Haraguchi M, Ozawa E, et al. Education and Imaging. Gastrointestinal: gastric mucosa-associated lymphoid tissue (MALT) lymphoma observed by magnifying endoscopy with narrow band imaging. J Gastroenterol Hepatol. 2012;27:987.

6. Ono S, Kato M, Ono Y, Itoh T, Kubota K, Nakagawa M, et al. Characteristics of magnified endoscopic images of gastric extranodal marginal zone B-cell lymphoma of the mucosa-associated lymphoid tissue, including changes after treatment. Gastrointest Endosc. 2008:68:624-31.

7. Damaj G, Verkarre V, Delmer A, Solal-Celigny P, Yakoub-Agha I, Cellier C, et al. Primary follicular lymphoma of the gastrointestinal tract: a study of 25 cases and a literature review. Ann Oncol. 2003;14:623-9.

8. Takata K, Okada H, Ohmiya N, Nakamura S, Kitadai Y, Tari A, et al. Primary gastrointestinal follicular lymphoma involving the duodenal second portion 
is a distinct entity: a multicenter, retrospective analysis in Japan. Cancer Sci. 2011;102:1532-6.

9. Yoshino T, Miyake K, Ichimura K, Mannami T, Ohara N, Hamazaki S, et al. Increased incidence of follicular lymphoma in the duodenum. Am J Surg Pathol. 2000;24:688-93.

10. Sakata H, Fujimoto K, Iwakiri R, Mizuguchi M, Koyama T, Sakai T, et al. Gastric lesions in 76 patients with adult T-cell leukemia/lymphoma: endoscopic evaluation. Cancer. 1996;78:396-402.

11. Shimoyama M. Diagnostic criteria and classification of clinical subtypes of adult T-cell leukaemia-lymphoma. A report from the lymphoma study group (1984-87). Br J Haematol. 1991;79:428-37.

12. Isomoto H, Matsushima K, Hayashi T, Imaizumi Y, Shiota J, Ishii H, et al. Endocytoscopic findings of lymphomas of the stomach. BMC Gastroenterol. 2013;13:174.

13. Nakamura S, Matsumoto T. Gastrointestinal lymphoma: recent advances in diagnosis and treatment. Digestion. 2013;87:182-8.

14. Kataoka K, Iwanaga M, Yasunaga JI, Nagata Y, Kitanaka A, Kameda T, et al. Prognostic relevance of integrated genetic profiling in adult T-cell leukemia/ lymphoma. Blood. 2018;131:215-25.

15. Haratake J, Horie A, Oda S, Chiba S, Kobori K, Sato H. A clinicopathological review of 12 autopsied cases of adult T-cell leukemia. Acta Pathologica Japonica. 1986:36:349-62.

16. Kataoka K, Nagata Y, Kitanaka A, Shiraishi Y, Shimamura T, Yasunaga Jl, et al. Integrated molecular analysis of adult T cell leukemia/lymphoma. Nat Genet. 2015;47:1304-15.

17. Bangham CR, Cook LB, Melamed A. HTLV-1 clonality in adult T-cell leukaemia and non-malignant HTLV-1 infection. Semin Cancer Biol. 2014;26: 89-98.

18. Cook LB, Melamed A, Niederer H, Valganon M, Laydon D, Foroni L, et al. The role of HTLV-1 clonality, proviral structure, and genomic integration site in adult T-cell leukemia/lymphoma. Blood. 2014;123:3925-31.

\section{Publisher's Note}

Springer Nature remains neutral with regard to jurisdictional claims in published maps and institutional affiliations.

Ready to submit your research? Choose BMC and benefit from:

- fast, convenient online submission

- thorough peer review by experienced researchers in your field

- rapid publication on acceptance

- support for research data, including large and complex data types

- gold Open Access which fosters wider collaboration and increased citations

- maximum visibility for your research: over $100 \mathrm{M}$ website views per year

At $\mathrm{BMC}$, research is always in progress.

Learn more biomedcentral.com/submissions 